\title{
Projects in Industry 4.0 framework and its effects on occupational safety
}

\author{
Nenad Milijić \\ Engineering Management Department, \\ University of Belgrade, Technical \\ Faculty in Bor, \\ Bor, Serbia \\ E-mail: nmilijic@tfbor.bg.ac.rs
}

\author{
Dejan Bogdanović \\ Engineering Management Department, \\ University of Belgrade, Technical \\ Faculty in Bor \\ Bor, Serbia \\ E-mail: dbogdanovic@tfbor.bg.ac.rs
}

\author{
Ivica Nikolić \\ Engineering Management Department \\ University of Belgrade, Technical \\ Faculty in Bor, \\ Bor, Serbia \\ E-mail: inikolic@tfbor.bg.ac.rs
}

\begin{abstract}
The fourth industrial revolution, or Industry 4.0, introduced a new level of production and transformed the use of digital integration and intelligent engineering. The essence of such initiatives is that manufacturers are able to satisfy a constantly changing demand by using flexible "smart" machines. However, the implementation of all the technologies used by the Industry 4.0 in production systems is not easy due to significant challenges. Therefore, it is necessary to identify and examine the challenges faced by manufacturing companies when trying to apply Industry 4.0. Occupational safety is certainly one of the most important challenges of the new production paradigm, to which adequate attention should be paid. This challenge is becoming even more pronounced in the project environment because of the temporary nature of the projects. In order to improve the level of occupational safety, its adequate analysis seems necessary. One way to do this is to compare the subject area in different contexts. In this paper, using the PROMETHEE tool, a multicriterial analysis of the effect of Industry 4.0 on occupational safety factors at industrial projects in Serbia was performed, compared to the previous industrial paradigm.
\end{abstract}

Keywords—projects, Industry 4.0, occupational safety, PROMETHEE.

\section{INTRODUCTION TO THE INDUSTRY 4.0 AND CHALLENGES OF THE WORKING ENVIRONMENT}

The beginning of industrialization and the rapid development of all economic activities started in the 18 th century. Since then, the industry has significantly transformed, and it is possible to distinguish several stages in its development. Certain technical and technological achievements and their mass application in the world were significant milestones and incentives of the new stages in industrialization. The introduction of machines powered by steam in 1784 represented the first significant phase. In this way, the manufacturing was free from the limitation of the human labour potential (The First Industrial Revolution- Steam power engine). The 19th century brought another significant industrial change in terms of the introduction of electrical energy. Thus, since 1870, a wide distribution of energy increased power and increased manufacturing capacities have been enabled (The Second Industrial Revolution- Mass production using electrical energy). The 20th century brought even greater industrial progress. First of all, the introduction of powered assembly lines, and later the development of electronics and information technologies, influenced the increasing automation of manufacturing. The manufacturing focus became performance-based. The need for manufacturing processes optimization rose. One likewise aspired to improve productivity through flexible machine design, as well as by improving ergonomics and safety. Therefore, in the history of industrialization, 1970 marks the beginning of a new stage (The Third Industrial Revolution - Use of IT systems for automation) [1, 2, 3].

The Fourth Industrial Revolution, or the Industry 4.0 , is ahead of us and progressing rapidly from day to day. This stage leads us to the next level of manufacturing where machines will be redefined in the way they would communicate and perform individual functions. However, Industry 4.0 is not just an industry. It is about the overall transformation of the use of digital integration and intelligent engineering. The concept of Industry 4.0 was defined by Kagermann et al. [4] connecting a virtual and realworld emphasizing engineering applications such as robotics, digitalization and automation [2]. The goal of Industry 4.0 is the convergence of manufacturing and digital revolution by the introduction of artificial intelligence, Internet of Things and Services and all devices called "smart". The essence of such initiatives is manufacturers being able to satisfy a constantly changing demand by more efficient use of adaptive and flexible machines and manufacturing systems [1, 5]. Hence, the productivity of the production systems is additionally increasing. This tendency transcends the design of individual machines and represents a broader vision that can be described as a global revolution in industrial manufacturing [1]. Industry 4.0 leads to the era of digitization in highly automated processes [6]. Everything is digital, starting with business models, environments, manufacturing systems, machines, equipment, operators and finally products and services. All of the above-mentioned elements are linked within a single digital space using an appropriate virtual display. This means that all physical flows are mapped on digital platforms. At this level of automation, sophisticated systems allow for the manufacturing systems to communicate both 
internally and externally in real-time. Thus, access to information and technology gets a completely new performance. This transformation of manufacturing companies already forms a smart paradigm [7]. The smart paradigm, or the digitization of products and services, become a necessity for a reliable industrial system in the 21 st century [2].

Industry 4.0 uses technologies such as Internet of Things - IoT and Internet of Services - IoS, humanmachine systems (Cyber-Physical Systems - CPS), industrial automation, additive manufacturing, continuous connectivity and information, cybernetic safety, intelligent robotics, semantic technologies, big data analysis, etc. $[1,2,8,9,10]$. This concept was created in Germany following the initiative of academics, industrialists and the Government, with the aim of strengthening the competitiveness of the industry through the interaction between industrial manufacturing and ICT [4, 8, 11]. The concept developed in the project has a tendency to expand and be applied in the industries of other countries. Of course, great efforts are being placed before the industries of these countries in order to meet all the challenges of the Industry 4.0 and reach the innovators of that concept [1].

In the context of Industry 4.0, a change in the working environment is required, hoping that it would bring significant benefits to the company in the future. In a wide range process of these changes and automation, employees must learn to deal with a new situation and new challenges, as well as to accept the concept of whole life learning [12]. Therefore, the implementation of the industry 4.0 in manufacturing systems cannot be done rapidly, but it is an incremental change [13]. It is important to highlight the elements on which such changes are focused. Industry 4.0 affects three elements of the business model in manufacturing - value creation, value acquisition and value offerings [14]. Companies should consider the Industry 4.0 very seriously since traditional manufacturing business models are not compatible with new technologies of the Industry 4.0 in most cases. Numerous questions need to be addressed very carefully: IT security, reliability of communication between machines; reliability of the human-machine system, maintenance of the integrity of manufacturing processes, protection of industrial knowledge, acquisition of adequate skills, promotion of the willingness for changes within stakeholders, etc. [11].

However, the implementation of Industry 4.0 in manufacturing systems is not easy due to significant challenges. Therefore, it is necessary to identify and examine the challenges faced by manufacturing companies when they are trying to apply the Industry 4.0 [15]. Challenges such as system and information reliability, system integrity, occupational safety, etc. represent bottlenecks that need to be overcome in order to successfully design and apply Industry 4.0 [2]. On the other hand, Industry 4.0 provides huge growth in industrialization and therefore, can disrupt the sustainability of current industrial systems. In addition, it can cause an environmental disbalance in the meaning of higher resource consumption, global warming, climate change and higher energy needs [5, $16,17]$. Industry 4.0 is trying to solve all these challenges in modern industrialization using the concept of sustainability. Finally, rapid industrialization also contributes to the degradation of occupational safety and this problem is becoming more pronounced [5]. Hence, apart from it being a legal obligation, risk management and occupational safety are becoming a moral obligation for companies [18]. As Industry 4.0 becomes the dominant reality, it will inevitably cause a change in the paradigm that will affect occupational safety management [1]. The challenge of occupational safety becomes even more underscored in project environment due to the temporary nature of projects [19]. In order to achieve satisfactory occupational safety, all managed performances of organizations must be considered with equal attention (productivity, quality, costs, execution time and impact on environmental and occupational safety) [20,21]

Currently, there is a small number of studies investigating occupational safety in the context of Industry 4.0. In the project environment, the number of such studies is even lower. Therefore, the aim of this paper is to analyze the impact of Industry 4.0 on occupational safety factors at contemporary industrial projects in Serbia.

\section{RESEARCH METHODOLOGY AND SAMPLE}

The source of the data used in this research are the assessments of the occupational safety factors at industrial projects in the context of the outgoing paradigm (Industry 3.0), as well as in the context of the upcoming Industry 4.0, based on the criteria set by 76 project managers. The methodology of the questionnaire was used to collect data. The questionnaire was developed by the authors of this paper, based on the available relevant literature [22, 23]. The questionnaire is composed of two parts. The first part contains 4 demographic questions. The second part of the questionnaire contains 17 questions related to the field of occupational safety. Experts (project managers) belong to the field of the construction industry (42), mechanical industry (23) and energetics (11), $71(93.4 \%)$ male and 5 (6.6\%) female. Educational level of project managers is: 1 (1.3\%) - high school; 15 (19.7\%) - higher education; $60(79 \%)$ - university.

Both industrial environments (Industry 3.0 and Industry 4.0) were assessed based on 4 occupational safety factors, following the five-point Likert scale, where 1 represents the smallest importance, and 5 represents the greatest importance. Each of the occupational safety factors (technical factors, human factors, organizational factors, and environmental factors) consisted of several indicators (sub-factors). Sub-factor estimates are summarized as occupational safety factor estimates. 
Using the PROMETHEE method, based on 4 criteria (occupational safety factors), a multicriteria analysis of occupational safety was performed $[22,23]$ in three types of industrial projects in the context of Industry 3.0 and in the context of Industry 4.0. In this way, a multicriteria analysis of 6 alternatives was performed. Additionally, project managers gave their expert opinion on the weight coefficients of the four ranking criteria used (by assignment of weight coefficients from 1 to 4 for each criterion).

TABLE I. ASSESSMENT OF OCCUPATIONAL SAFETY FACTORS IN INDUSTRIAL SECTORS IN CONTEXT I 3.0 AND CONTEXT I 4.0

\begin{tabular}{|l|l|l|l|l|}
\hline $\begin{array}{l}\text { Criterions for assessing occupational security on } \\
\text { projects in the context of industry 3.0 and 4.0 }\end{array}$ & $\begin{array}{l}\text { Technical } \\
\text { factors }\end{array}$ & Human factors & $\begin{array}{l}\text { Organizational } \\
\text { factors }\end{array}$ & $\begin{array}{l}\text { Environmental } \\
\text { factors }\end{array}$ \\
\hline Construction industry - I 3.0 & 3.9 & 4.4 & 3.8 & 3.3 \\
\hline Construction industry - I 4.0 & 4.3 & 2.9 & 2.5 & 2.8 \\
\hline Mechanical industry - I 3.0 & 3.3 & 3.9 & 4.1 & 2.9 \\
\hline Mechanical industry - I 4.0 & 4.6 & 3.7 & 3.8 & 3.1 \\
\hline Energetics - I 3.0 & 4.6 & 4.5 & 4.2 & 4.0 \\
\hline Energetics - I 4.0 & 4.5 & 3.1 & 3.6 & 3.7 \\
\hline
\end{tabular}

\section{RESULTS AND DISCUSSION}

\section{PROMETHEE calculations}

After collecting the input data by interviewing experts, setting of the preference function, normalizing of the weighting coefficients of the criterions, and forming the evaluation matrix (Table II) using the Visual PROMTHEE software package, ranking of the occupational safety was performed on the three types of industrial projects in the context of Industry 3.0 and in the context of Industry 4.0.

TABLE II. PREFERENCE FUNCTION AND WEIGHT COEFFICIENTS FOR OCCUPATIONAL SAFETY CRITERIA

\begin{tabular}{|l|l|l|l|l|}
\hline Criterion & Mark & $\begin{array}{l}\text { Weight } \\
\text { coefficient }\end{array}$ & $\begin{array}{l}\text { Preference } \\
\text { function }\end{array}$ & max/min \\
\hline Technical factors & KOS-1 & 0.189 & Linear & max \\
\hline Human factors & KOS-2 & 0.322 & Linear & max \\
\hline Organizational factors & KOS-3 & 0.276 & Linear & $\max$ \\
\hline Environmental factors & KOS-4 & 0.213 & Linear & $\max$ \\
\hline
\end{tabular}

The PROMETHEE method is based on determining the positive $\left(\phi^{+}\right)$and negative flow $\left(\phi^{-}\right)$ for each of the alternatives. A positive flow of preferences shows how much a particular alternative is preferable over other alternatives. If the value is greater $\left(\phi^{+} \rightarrow 1\right)$, the alternative is more important than other alternatives. A negative preference flow indicates how much a particular alternative is preferred by other alternatives. The alternative is more important if the flow value is lower $\left(\phi^{-} \rightarrow 0\right)$. Complete ranking according to the PROMETHEE II method is based on the calculation of the net flow $(\phi)$ (distinction between the positive and the negative flows of the preference). An alternative with the highest net flow value is best-ranked, following in descending order to the worst-ranked alternative [24, $25,26]$. On the basis of the above mentioned and assigned parameters of the criteria and alternatives, the complete ranking was performed (PROMETHEE II). In this case, the ranking of occupational safety was performed in three types of industrial projects in the context of Industry 3.0 and in the context of Industry 4.0. The obtained results are presented in Fig. 1. Judging by the obtained results, it is noted that alternative 5 was the best-ranked alternative (Energetics I 3.0). This means that project managers estimated that the level of occupational safety was the most favourable on projects in the field of energetics in the current industry paradigm 3.0. On the other hand, according to the experts' estimates, the worstranked alternative was alternative 2 (Construction Industry I 4.0). It can be concluded that the level of occupational safety on energetics projects as well as on construction projects is more favourable within the current industry paradigm 3.0 compared to the level of occupational safety within these projects in the context of Industry 4.0. For projects that are realized in the field of mechanical industry, the level of occupational safety is more favourable in the context of Industry 4.0 compared to the level of occupational safety in the context of Industry 3.0.

The visual PROMTHEE software package offers a visual comparison of alternatives according to each criterion - GAIA plane. With the GAIA plane, it is very easy to define strength or weakness, also the quality of each alternative following each criterion. Moreover, the strength of the criteria influence on ranking can be determined. Fig. 2 shows the position of the six considered alternatives at the GAIA plane, as well as the criteria of the performed ranking. The alternatives are shown as squares and the criteria of the axes ending with rhombs. Observing the peculiarity of the position of the criteria, i.e. their distance from the origin, it is obvious that the criterion KOS-2 (human factors) and criterion KOS-3 (organizational factors) are more influential than the 
other two criteria. Additionally, the KOS-2 and KOS-3 criteria are closest to the decision stick pi, which verify their biggest impact. The position of the alternative show its strength or weakness related to the criteria. If an alternative is closer to the axis orientation of a criterion, this alternative is better according to that criterion. Alternative 5 (Energetics I 3.0 ) is the most favourable option since it is very close to the axes orientation of the criterion with the biggest impact (KOS-2 and KOS-3). Additionally, unlike the other alternatives, alternative 5 is more closely

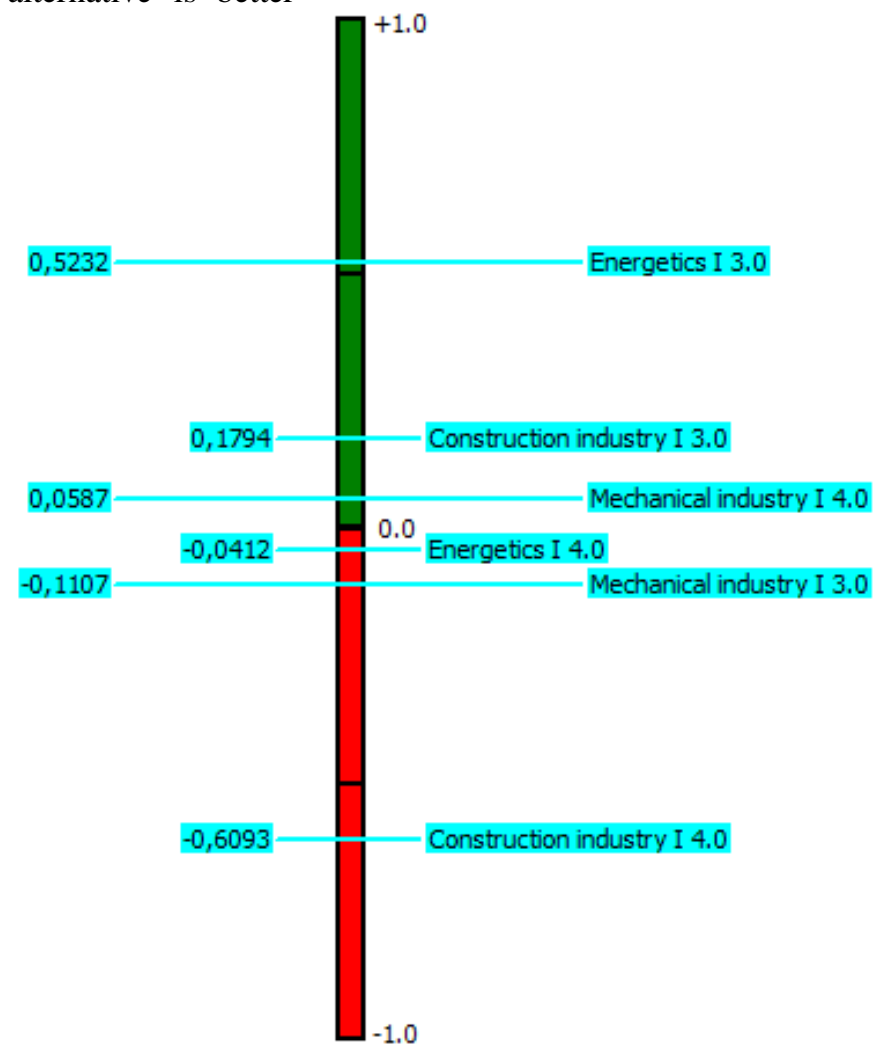

Fig. 1. PROMETHEE II completely ranking of the occupational safety in different industrial sectors in the context of I 3.0 and in the context of I 4.0

positioned to the other two criteria. The decision stick is displayed by an axis that ends with a circle. It represents an optimal solution consistent with the given weight criteria. The best one is an alternative that is closest to the decision stick [25], and that is alternative 5 (Energetics I 3.0). In other words, the level of occupational safety is more favourable at projects in the field of energetics in the context of Industry 3.0. Additionally, at GAIA plane, it can be seen that all three types of projects in the context of Industry 4.0 are under a very strong influence of the KOS-1 criterion (technical factors). This result confirms theoretical and practical knowledge that the Industry 4.0 is actually the industry of robotics, digitalization and automation, and that it is technically and technologically dominant in relation to Industry 3.0 [2]. Technical sub-factors that provide the dominant position of occupational safety in the context of Industry 4.0 are the following: analysis of criteria and selection of safety levels; assessment of accidents at work and quantification; the frequency of defects and intensity of consequences; reliability; maintenance rate and maintenance costs. On the other hand, all three types of projects in the context of Industry 3.0 are under a very strong influence of the (human factors), KOS-3 (organizational factors) and KOS-4 (environmental factors) criteria. This confirms that policies, strategies and procedures of occupational safety in the context of Industry 3.0 are theoretically and practically much more developed compared to the same area in the context of Industry 4.0, which is still in development. Human sub-factors that need to be improved are the following: competence and knowledge; effective safety training; efficiency of teamwork. Regarding the organizational sub-factors that need to be improved, the most important are: the efficiency of the occupational safety management; i.e. safety procedures. Finally, considering the environmental sub-factors, it is necessary to improve the level of implementation of legal procedures; i.e. implementation of standards.

\section{Sensitivity analysis}

To determine the range of the preferred relationships with the obtained ranking, analysis of the sensitivity of weight coefficients of the criteria was performed (Table III). By sensitivity analysis can be determined the stability intervals for each criterion. The stability interval establishes the boundaries within which the range of weight coefficients of the criterion can be changed without affecting the previous ranking solution. On this occasion, the weight of only one criterion was changed, while the relative weight of the remaining criterions remained unchanged [27]. 


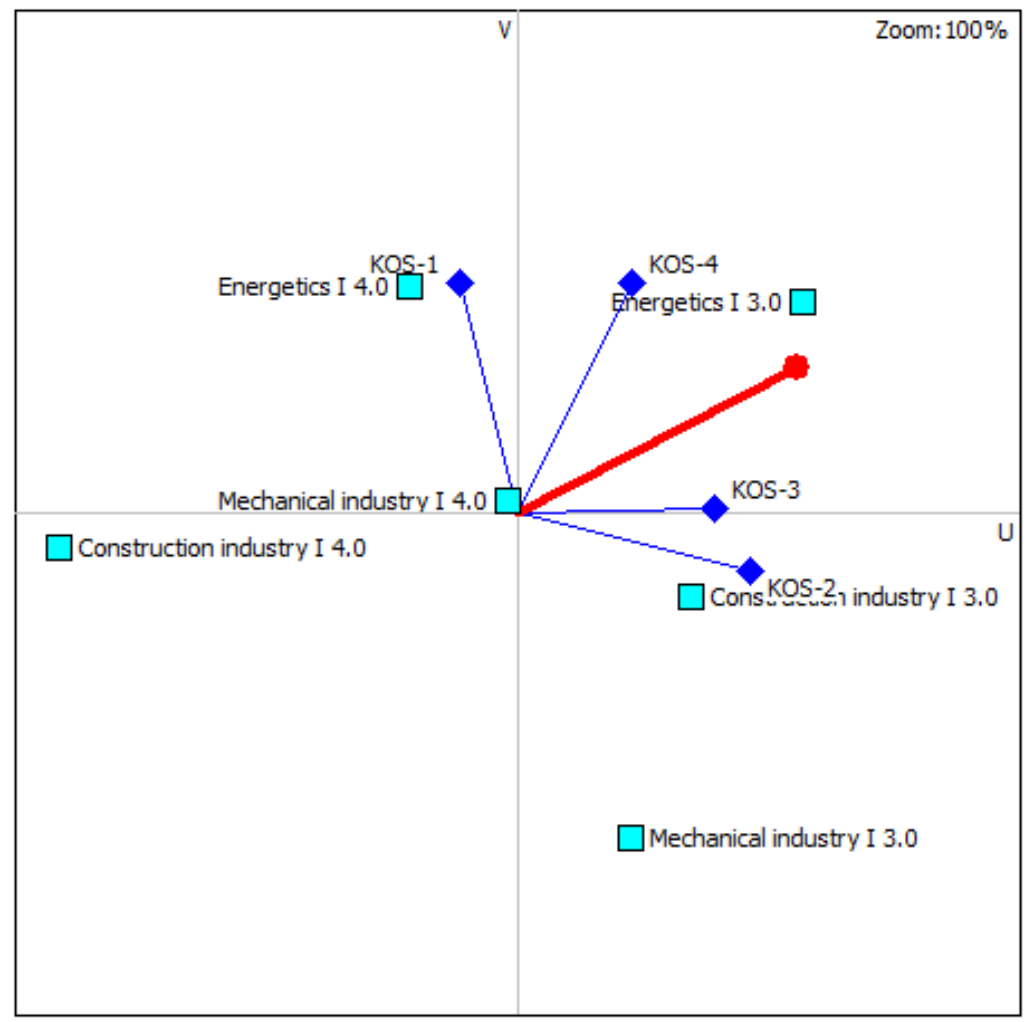

Fig. 2. GAIA plane for the selection of the most favourable industrial alternative in terms of occupational safety

TABLE III. INTERVALS OF STABILITY OF WEIGHT COEFFICIENTS OF OCCUPATIONAL SAFETY CRITERIA

\begin{tabular}{|l|l|l|l|l|}
\hline Criterion & Mark & \multirow{2}{*}{\begin{tabular}{l} 
Weight \\
coefficient \\
\cline { 4 - 5 }
\end{tabular}} & & \multicolumn{2}{|l|}{ Stability intervals (\%) } \\
\cline { 4 - 5 } & & Min & max \\
\hline Technical factors & KOS-1 & 19 & 13.87 & 33.57 \\
\hline Human factors & KOS-2 & 32 & 21.16 & 37.43 \\
\hline Organizational factors & KOS-3 & 28 & 0.00 & 41.56 \\
\hline Environmental factors & KOS-4 & 21 & 15.39 & 30.19 \\
\hline
\end{tabular}

Based on the obtained results of sensitivity analysis of weight coefficients of the criteria, it can be noted that the change in the rank order would occur if the value of the weight coefficient of the KOS-1 criterion (technical factors) decreased by more than $5.13 \%$, or increased by more than $14.57 \%$; KOS-2 criterion (human factors) decreased by more than $10.84 \%$, or increased by more than $5.43 \%$; KOS-4 criterion (environmental factors) decreased by more than $5.61 \%$, or increased by more than $9.19 \%$. KOS-3 criterion (organizational factors) exhibits the widest interval of stability. Namely, the value of this weighting coefficient can be extremely decreased without affecting the obtained ranking solution, while the change of the solution would only appear after the value of the weight coefficient increased by more than $13.56 \%$.

\section{CONCLUSION}

The advantages of doing business in the context of Industry 4.0 are unquestionable; however, whether and when occupational safety could be improved compared to the previous industrial paradigm, remains an open question. The results of the carried out multicriterial analysis of the occupational safety level during the realization of various industrial projects in the context of the outgoing paradigm of the Industry 3.0 on the one hand, and coming paradigm of the Industry 4.0 on the other hand, shown in this paper, favour Industry 3.0. Considering that a survey was conducted on the population of project managers engaged in projects realized in Serbia, where the preconditions for full implementation of the Industry 4.0 are still incomplete, such a result is expected. Furthermore, safety procedures and practices, safety training, competencies and other occupational safety elements are still more appropriate to the traditional business context (Industry 3.0). However, sensitivity analysis of weight coefficients used in the ranking of the occupational safety levels on three types of industrial projects in the context of Industry 3.0 and in the context of Industry 4.0 shows that the advantage of the environment of the Industry 3.0 relative to the environment of the Industry 4.0 is not absolute. Under 
different circumstances, relatively small changes could result in a different solution. The final conclusion based on measuring project managers' perception is that in the industrial sector of Serbia, occupational safety within the Industry 4.0 represents a still inadequately developed and implemented area. The most likely reason for this is the insufficient implementation of the Industry's 4.0 preconditions being the essence of a new way of doing business, i.e. profit-making, and in such an environment, occupational safety, as a segment of business which indirectly generates profit, remains of secondary importance.

\section{REFERENCES}

[1] A. Badri, B. Boudreau-Trudel, and A.S. Souissi, "Occupational health and safety in the industry 4.0 era: A cause for major concern?", Safety Science, vol. 109, 2018, pp. 403-411.

[2] P.K. Muhuri, A.K. Shukla, and A. Abraham, "Industry 4.0: A bibliometric analysis and detailed overview", Engineering Applications of Artificial Intelligence, vol. 78, 2019, pp. 218 235.

[3] S. Vaidya, P. Ambad, and S. Bhosle, "Industry 4.0 - A Glimpse", Procedia Manufacturing, vol. 20, 2018, pp. 233 238.

[4] H. Kagermann, W. and J. Wahlster, "Recommendations for implementing the strategic initiative INDUSTRIE 4.0", In: Final report of the Industrie 4.0 Working Group. Acatech, Frankfurt am Main, Germany, 2013.

[5] S. Luthra, and S.K. Mangla, "Evaluating challenges to Industry 4.0 initiatives for supply chain sustainability in emerging economies", Process Safety and Environmental Protection, vol. 117, 2018, pp. 168-179.

[6] Y. Lu, "Industry 4.0: A survey on technologies, applications and open research issues", Journal of Industrial Information Integration, vol. 6, 2017, pp. 1-10.

[7] V. Alcácer, and V. Cruz-Machado, "Scanning the Industry 4.0: A Literature Review on Technologies for Manufacturing Systems", Engineering Science and Technology, an International Journal. Article in press.

[8] F. Baena, A. Guarin, J. Mora, J. Sauza, and S. Retat, "Learning Factory: The Path to Industry 4.0", Procedia Manufacturing, vol. 9, 2017, pp. 73-80.

[9] S.S. Kamble, A. Gunasekaran, and R. Sharma, "Analysis of the driving and dependence power of barriers to adopt industry 4.0 in Indian manufacturing industry", Computers in Industry, vol. 101, 2018, pp. 107-119.

[10] A. Telukdarie, E. Buhulaiga, S. Bag, S. Gupta, and Z. Luo, "Industry 4.0 implementation for multinationals", Process Safety and Environmental Protection, vol. 118, 2018, pp. 316-329.

[11] T.K. Sung, "Industry 4.0: A Korea perspective", Technological Forecasting \& Social Change, vol. 132, 2018, pp. $40-45$.

[12] M. Trstenjak, and P. Cosic, "Process planning in Industry 4.0 environment", Procedia Manufacturing, vol. 11, 2017, pp. $1744-1750$.
[13] A. Benešová, and J. Tupa, "Requirements for Education and Qualification of People in Industry 4.0", Procedia Manufacturing, vol. 11, 2017, pp. 2195-2202.

[14] J.M. Müller, O. Buliga, and K.-I. Voigt, "Fortune favors the prepared: How SMEs approach business model innovations in Industry 4.0", Technological Forecasting \& Social Change, vol. 132, 2018, pp. 2-17.

[15] M.A. Moktadir, S.M. Ali, S. Kusi-Sarpong, and M.A. Ali Shaikh, "Assessing challenges for implementing Industry 4.0: Implications for process safety and environmental protection", Process Safety and Environmental Protection, vol. 117, 2018, pp. 730-741

[16] F. Hecklau, M. Galeitzke, S. Flachs, and H. Kohl, "Holistic approach for human resource management in Industry 4.0", Procedia CIRP, vol. 54, 2016, pp. 1-6.

[17] M.L. Tseng, Q. Zhu, J. Sarkis, and A.S. Chiu, "Responsible consumption and production in corporate decision-making models", Industrial Management \& Data Systems, vol. 118(2), 2018. pp. 322-329.

[18] J. Tupa, J., Simota, and F. Steiner, "Aspects of risk management implementation for Industry 4.0", Procedia Manufacturing, vol. 11, 2017, pp. 1223-1230.

[19] N. Milijić, A. Jovanović, and I. Mihajlović, I. "Occupational safety during the execution of investment projects in Serbia", XVIII International Symposium on Project Management YUPMA 2014 - Book of Proceedings, 2014, pp. 297-301. (in Serbian)

[20] J. Lee, S. Jun, T.W. Chang, and J. Park, "A smartness assessment framework for smart factories using analytic network process", Sustainability, vol. 9(5), 2017, pp. $794-$ 808 .

[21] S. Mittal, M.A. Khan, D. Romero, and T. Wuest, "A critical review of smart manufacturing \& Industry 4.0 maturity models: Implications for small and medium-sized enterprises (SMEs)", Journal of Manufacturing Systems, vol. 49, 2018, pp. 194-214.

[22] G. Janaćković, S. Savić, and M. Stanković, "Selection and ranking of occupational safety indicators based on fuzzy AHP: case study in road construction companies", The South African Journal of Industrial Engineering, vol. 24(3), 2013, pp. $175-189$.

[23] N. Milijić, I. Mihajlović, N. Štrbac, and Ž. Živković, "Developing a Questionnaire for Measuring Safety Climate in the Workplace in Serbia", International Journal of Occupational Safety and Ergonomics, vol. 19(4), 2013, pp. 631-645.

[24] G. Anand, and R. Kodali, "Selection of lean manufacturing systems using the PROMETHEE", Journal of Modelling in Management, vol. 3(1), 2008, pp. 40-70.

[25] J.P. Brans, and B. Mareschal, "The PROMCALC and GAIA decision support system for multicriteria decision aid", Decision Support Systems, vol. 12, 1994, pp. 297-310.

[26] J.P. Brans, P.H. Vincke, and B. Mareschal, "How to select and how to rank projects: The Promethee method", European Journal of Operational Research, vol. 24(2), 1986, pp. 228238.

[27] N.A.V. Doan, and Y. De Smet, "An alternative weight sensitivity analysis for PROMETHEE II rankings", Omega, vol. 80, 2018, pp. 166-174. 